\title{
Local therapies for inflammatory eye disease in translation: past, present and future
}

Shenzhen Tempest-Roe ${ }^{1}$, Lavnish Joshi ${ }^{1,2,3}$, Andrew D Dick ${ }^{3,4,5}$ and Simon RJ Taylor ${ }^{1,2^{*}}$

\begin{abstract}
Despite their side-effects and the advent of systemic immunosuppressives and biologics, the use of corticosteroids remains in the management of patients with uveitis, particularly when inflammation is associated with systemic disease or when bilateral ocular disease is present. The use of topical corticosteroids as local therapy for anterior uveitis is well-established, but periocular injections of corticosteroid can also be used to control mild or moderate intraocular inflammation. More recently, intraocular corticosteroids such as triamcinolone and steroid-loaded vitreal inserts and implants have been found to be effective, including in refractory cases. Additional benefits are noted when ocular inflammation is unilateral or asymmetric, when local therapy may preclude the need to increase the systemic medication.

Implants in particular have gained prominence with evidence of efficacy including both dexamethasone and fluocinolone loaded devices. However, an appealing avenue of research lies in the development of non-corticosteroid drugs in order to avoid the side-effects that limit the appeal of injected corticosteroids. Several existing drugs are being assessed, including anti-VEGF compounds such as ranibizumab and bevacizumab, anti-tumour necrosis factor alpha antibodies such as infliximab, as well as older cytotoxic medications such as methotrexate and cyclosporine, with varying degrees of success. Intravitreal sirolimus is currently undergoing phase 3 trials in uveitis and other inflammatory pathways have also been proposed as suitable therapeutic targets. Furthermore, the advent of biotechnology is seeing advances in generation of new therapeutic molecules such as high affinity binding peptides or modified high affinity or bivalent single chain Fab fragments, offering higher specificity and possibility of topical delivery.
\end{abstract}

\section{Introduction}

Inflammatory eye disease encompasses a wide range of clinical phenotypes, and uveitis can be classified anatomically into either anterior, intermediate and posterior uveitis or panuveitis; and as acute or chronic disease, depending on whether it lasts more or less than 3 months in duration [1]. The Standardisation of Uveitis Nomenclature (SUN) criteria now form the standard for reporting uveitis clinical data [2]. The commonest type is acute anterior uveitis, in which $50 \%$ of people are HLA B27 positive, although they do not necessarily have an associated systemic disorder [3]. Chronic anterior uveitis lasts longer than 3 months and may or may not be associated with systemic disease. The rest of the disorders tend to be chronic, and the more serious types

\footnotetext{
* Correspondence: s.r.taylor@imperial.ac.uk

${ }^{1}$ Faculty of Medicine, Imperial College London, London, UK

${ }^{2}$ Royal Surrey County Hospital NHS Foundation Trust, Guildford, Surrey, UK

Full list of author information is available at the end of the article
}

with posterior segment involvement have an increased incidence of visual loss, and approximately half of these patients have an associated systemic disease.

Corticosteroids remain the mainstay of treatment of all types of uveitis. Anterior uveitis is treated to control symptoms of pain, photophobia and redness, and to reduce complications such as posterior synechiae, cataract and macular oedema. Posterior segment inflammation usually requires treatment as it generates sight-threatening sequelae such as retinitis, macular oedema, optic disc oedema, chorioretinitis and retinal vasculitis. Topical corticosteroids are inadequate for this as they do not penetrate beyond the lens, so oral corticosteroids and second-line immunosuppressive agents are used, particularly in patients with an associated systemic disease and in those with bilateral ocular inflammation requiring treatment. Nevertheless, systemic administration is associated with significant side-effects, so there has been increasing

\section{Biomed Central}

(c) 2013 Tempest-Roe et al.; licensee BioMed Central Ltd. This is an Open Access article distributed under the terms of the Creative Commons Attribution License (http://creativecommons.org/licenses/by/2.0), which permits unrestricted use, distribution, and reproduction in any medium, provided the original work is properly cited. 
interest in the local delivery of drugs to the eye and periocular tissues in order to avoid these complications.

This approach is not new. Traditionally, periocular injections of corticosteroids such as triamcinolone and methlyprednisolone have proved effective in controlling vitritis and mild to moderate macular edema in unilateral disease, but their use is limited by the need for repeat injections, IOP rises in corticosteroid responders and the induction of ptosis, orbital fat atrophy or orbital fat protrusion as a consequence of both the corticosteroid and the mode of injection [4,5]. More recently, intraocular delivery of corticosteroids has become widespread. Initially triamcinolone was used, but long-acting inserts are now becoming available, e.g. Retisert (Bausch \& Lomb, Rochester, NY, USA) and Ozurdex (Allergan, Irvine, CA, USA).

Nevertheless, the local side-effects of corticosteroid delivery remain. Care also needs to be taken in cases of diagnostic uncertainty to ensure that there is not an infective cause for the uveitis, as this may be worsened by local therapy and depot corticosteroids can be difficult to remove, whereas oral corticosteroids can be rapidly stopped.

Owing to these side-effects, researchers have tried to move towards new non-corticosteroid alternatives. Some of these are old drugs, such as methotrexate, and others are based on the new so-called biological agents, in which monoclonal antibodies are directed against specific targets within the immune system, such as the anti-tumour necrosis factor (TNF)-alpha agents and the anti-vascular endothelial growth factor (VEGF) agents. This review article aims to outline agents currently in use for the local therapy of non-infectious uveitis, as well as those currently in translation from the laboratory to clinical use.

\section{Review \\ Topical and subconjunctival therapy for ocular inflammatory disease}

Topical corticosteroids have provided the mainstay of treatment for anterior uveitis since the 1950s, but do not penetrate far enough into the eye to control intermediate or posterior disease [6]. Their side-effects include cataract formation and raised intraocular pressure, in common with all corticosteroids, and are related to the strength of the corticosteroid and ocular penetration [6].

\section{Corticosteroids}

Dexamethasone sodium $0.1 \%$ and prednisolone acetate $1 \%$ are widely used and are broadly equivalent; difluprednate $0.05 \%$ has recently been introduced to the US and is considered more potent [7]. Rimexolone is a topical corticosteroid that was specifically engineered to generate less of an intraocular pressure rise by the elimination of a hydroxyl group. Randomised Controlled
Trials (RCTs) suggest that it probably does induce less of a rise in intraocular pressure than either dexamethasone sodium $0.1 \%$ or prednisolone acetate $1 \%$ (the differences did not reach statistical significance [8]), but it is a weaker corticosteroid that is most useful in controlling chronic anterior uveitis in patients with established glaucoma or who are corticosteroid responders. Similarly, loteprednol etabonate $0.5 \%$ is associated with less of an intraocular pressure rise than prednisolone acetate $1 \%$ [9], but also has a reduced ability to control anterior chamber inflammation [9].

Subconjunctival corticosteroids in the form of dexamethasone or betamethasone may also be useful in the short-term treatment of severe anterior uveitis [10], and triamcinolone has recently been shown to be effective in the management of anterior scleritis without inducing necrotising disease, having a longer duration of effect than dexamethasone and betamethasone [11].

\section{Non-steroidal anti-inflammatory drugs}

Cyclooxygenase is a critical enzyme in the inflammatory process and catalyzes the biosynthesis of prostaglandins that disrupt the blood-ocular barrier, increase vasodilation, and facilitate leukocyte migration [12]. Non-steroidal antiinflammatory drugs (NSAIDs) are potent inhibitors of cyclooxygenase enzymes and can be administered topically for the treatment of postoperative inflammation and macular oedema, either with or without concurrent corticosteroid administration [13].

\section{Other agents}

There are no other topical anti-inflammatory agents in widespread use for the treatment of uveitis. Topical Cyclosporine A was examined in several studies from the 1980s $[14,15]$, but was shown to be ineffective in human disease. A study of the subconjunctival administration of sirolimus for intermediate or posterior uveitis was recently reported in which it was found to be safe and well tolerated (see Section "Anti-Tumour Necrosis Factor (TNF)- $\alpha$ agents" below) [16]; the results of a Phase 3 trial are awaited.

\section{Periocular therapy for ocular inflammatory disease}

The numerous side-effects of oral corticosteroids are well-known and include gastric ulcers, weight gain, psychological disturbances, osteoporosis, diabetes, hypertension and suppression of growth in children [17]. In patients with unilateral or asymmetric disease, or in whom systemic administration of medication is less desirable, e.g. during pregnancy or in patients with a history of gastric ulceration, periocular injection can be useful to provide a depot of corticosteroid that successfully reaches the posterior segment to control inflammation [18-20]. 


\section{Periocular corticosteroids}

The precise mechanisms by which locally injected corticosteroids enter the eye are not known [21], but systemic drug levels remain low, and corticosteroids can be found in all layers of the eye, even at 30 days after a single subtenon injection of $40 \mathrm{mg}$ of triamcinolone acetate, the highest levels being found in the choroid and retinal pigment epithelium [22]. Periocular corticosteroid injections can be administered either via the subtenon route or as an orbital floor injection [18]. Both procedures are safe, with a low risk of ocular penetration and of developing other side-effects of corticosteroid administration such as raised intraocular pressure and cataract [23-25]. The duration of effect is approximately 2 months [26].

\section{Other periocular agents}

Currently no other non-corticosteroid agents are injected periocularly for the treatment of ocular inflammatory disease.

\section{Intraocular corticosteroid therapy for ocular inflammatory disease}

Intravitreal injections are now commonplace in ophthalmology, and are used for the treatment for a variety of ocular inflammatory and medical retinal disorders. The injection of dexamethasone into the vitreous had previously been used as an adjunct to vitrectomy, but it remains in the eye at therapeutic levels for hours only $[27,28]$, and thus was superseded by triamcinolone as the intravitreal corticosteroid of choice. Triescence and Trivaris are triamcinolone preparations that are licenced for intraocular use in the US, but neither is available in the Europe, and Kenalog is commonly used off-label instead. However triamcinolone has a considerable side-effect profile in terms of cataract formation and raised intraocular pressure [29]. The injection-related side effects of intravitreal therapy resemble those of any other intraocular injection, and include endophthalmitis, intravitreal haemorrhage, rhegmatogenous retinal detachment, although these are rare. Other corticosteroid and non-corticosteroid agents have subsequently been developed, including sustained-release implants.

\section{Intravitreal corticosteroid injections}

Intravitreal injection of triamcinolone acetate (IVTA) in the treatment of uveitis is now commonplace, and involves the injection of corticosteroid directly into the vitreous body, thus achieving a higher concentration of intraocular corticosteroid [30]. The consensus for the recommended dosage of IVTA is $4 \mathrm{mg}$, and the typical duration of effect is $3-4$ months [31,32]. IVTA is most commonly used for the treatment of inflammatory cystoid macular oedema [33,34]. The systemic sideeffects of IVTA are limited, as the triamcinolone is confined to the eye and serum levels have been shown not to be significant [35], but raised intraocular pressure is seen in $29-50 \%$ of patients within a year [33]. In most cases this can be controlled medically, but there have been a few reports of patients requiring surgical intervention [36]. Cataract development is also a common side-effect of IVTA in uveitic patients, and the rate of cataract progression is reported to be increased five-fold, particularly after multiple injections [29].

\section{Short- and medium-acting intravitreal corticosteroid implants}

The Surodex anterior segment delivery system (Oculex Pharmaceuticals, Sunnyvale, CA, USA) was designed to control inflammation after cataract surgery, and consists of a biodegradable device that is inserted into the anterior chamber and allows sustained release of corticosteroid over a period of seven days. It contains $60 \mu \mathrm{g}$ dexamethasone incorporated into a polymer matrix of poly(lactic-glycolic)-acid, and achieves higher intraocular drug levels than conventional dexamethasone eye drops [37]. It is effective in the control of post-cataract surgery inflammation [37-39] but, as it only lasts for seven days, its usefulness does not extend beyond post-operative uveitis, and is not in widespread use.

The Ozurdex 'bio-erodible' dexamethasone implant is now licensed for the treatment of uveitis in the USA and Europe. This uses a solid polymer delivery system, in which biodegradable material is combined with dexamethasone to form a small rod-shaped implant which is injected into the vitreous using a specially designed injector. Dexamethasone is released over about 6 months, the pharmacokinetics demonstrating a high initial concentration peak in the vitreous followed by a longer period of low-level release before the implant dissolves completely to $\mathrm{H}_{2} \mathrm{O}$ and $\mathrm{CO}_{2}$, leaving no residue [40]. This has been shown to be effective in both adult [41] and paediatric [42] uveitis and it is hoped that it will cause less raised intraocular pressure and cataract than triamcinolone, but the phase III trial included only one implant and excluded steroid responders. Further data are awaited.

\section{Long-acting intravitreal corticosteroid implants}

Retisert is a long-term slow release intravitreal implant, which was based on those used to deliver ganciclovir to patients with cytomegalovirus retinitis, but which is smaller in size. The chosen corticosteroid is fluocinolone acetonide as it has high potency, low solubility and a very short duration of action in the systemic circulation, enabling the steroid pellet to be small, and reducing the risk of systemic side-effects. The implant is surgically placed into the vitreous cavity and pharmacokinetic 
studies in rabbits have demonstrated the delivery of constant levels of the corticosteroid to the posterior pole with no evidence of systemic absorption over approximately 2.5 years $[43,44]$.

Its efficacy has been demonstrated in large studies [45], but it induces marked cataract formation such that all patients require cataract surgery within 3 years [45]. Significantly raised intraocular pressure is also very common, with up to $40 \%$ of patients requiring trabeculectomy surgery [45]. Additional side-effects include scleral thinning over the implant in some cases, vitreous band formation, and the development of cytomegalovirus retinitis and endotheliitis [46]. In view of its effects on intraocular pressure and cataract, it is worth noting that insertion of the implant can be combined safely with glaucoma drainage device placement [47] or with phacoemulsification and intraocular lens insertion [48].

The Multicenter Uveitis Steroid Treatment (MUST) trial compare local control of intermediate and posterior uveitis with Retisert implants (implanted bilaterally for bilateral disease) with aggressive oral systemic therapy, and found no significant differences between each treatment arm at two years in terms of vision, although macular oedema did appear to be better controlled in the implant arm [49]. The trial has recently been extended for a further four years to see whether significant differences emerge over a longer timespan.

\section{Other intravitreal corticosteroid inserts}

Iluvien (Alimera Sciences, Alpharetta, GA, USA) is another fluocinolone acetonide intravitreal insert which is designed to deliver corticosteroid to the retina for up to three years as a treatment for diabetic macular oedema [50]. It uses the same drug matrix as Retisert, but is thought to release a lower dose of drug $(0.2 \mu \mathrm{g} /$ day or $0.5 \mu \mathrm{g} /$ day) than Retisert (nominally $0.59 \mu \mathrm{g} /$ day) [50], and is injected through a proprietary 25-gauge injector system in an outpatient setting, in contrast to the surgical setting required to implant the Retisert device. Phase II studies in diabetic macular oedema suggest the possibility of a lower rate of IOP rise than with Retisert, although the numbers in the study were relatively small, the follow-up period short, and there was still significant incidence of cataract progression, suggesting the occurrence of significant corticosteroid side-effects [51]. There is no published evidence for its use in uveitis. The I-Vation implant (SurModics, Eden Prairie, MN, USA) is based around triamcinolone, and is reported to have a duration of release of over a year. It has a unique implantation mechanism in which a screwshaped device is twisted through the pars plana, although little published data is currently available on its use [50,52].

\section{Intravitreal non-corticosteroid therapy for ocular inflammatory disease}

In an attempt to avoid the ocular side-effects of intraocular corticosteroids, attention has been focused on the development of other agents. This has involved the trial of both established immunosuppressive agents and also the novel so-called biological therapies, with varying degrees of success.

\section{Non-steroidal anti-inflammatory drugs}

Ketorolac does not reach significant levels in the vitreous or retina after topical or systemic application [12,53]. A recent prospective phase I trial of intravitreal ketorolac in ten patients showed some effect in treating intraocular inflammation and macular oedema [54]. However, a similar pilot study of intravitreal diclofenac showed no benefit [55].

\section{Conventional immunosuppressive agents}

Intraocular methotrexate has long been used to treat intraocular lymphomas associated with primary central nervous system lymphoma [56,57], but has more recently been tried in uveitis $[58,59]$. In one prospective study it was found to be effective in reducing vitritis and macular oedema without raising the IOP in patients with a history of steroid response. Interestingly, the onset of effect was within one week and lasted approximately three months, with no statistical difference between the best visual acuity obtained after methotrexate injection and after previous corticosteroid treatment, including IVTA injection [59]. A larger collaborative series is currently in press and has suggested that this drug may induce longer-term remission in some patients $[60,61]$.

There is some published evidence of the successful use of cyclosporine-loaded poly(lactic co-glycolic) spheres in animal models [62], but this has not been successfully translated into the treatment of human disease. Intravitreal tacrolimus has shared a similar fate $[63,64]$.

\section{Anti-vascular endothelial growth factor (VEGF) agents}

VEGF inhibition has also been tried as a noncorticosteroid intraocular treatment for uveitic CME, owing to its induction in inflammation, its role in increasing vascular permeability and the finding of increased levels in eyes with uveitic macular oedema [65-69]. Several small retrospective studies have been reported using both bevacizumab and ranibizumab, although bevacizumab is more commonly used owing to its lower cost. Intravitreal bevacizumab does appear effective in reducing central macular thickness, but the studies do not generally suggest a statistically significant increase in visual acuity $[65,70,71]$. Similar results have been achieved with ranibizumab [72]. 
Interestingly, three studies have compared the use of anti-VEGF treatment to IVTA in the treatment of uveitis-associated CME. Two retrospective reports comprising 31 eyes treated with IVTA and 26 eyes treated with intravitreal bevacizumab indicated a trend for better visual improvement and decreased macular thickness in IVTA-treated eyes [73,74]. A further prospective report with longer follow-up indicated an improved visual outcome for eyes treated with IVTA, once the confounding effect of cataract had been removed [75].

Similar to methotrexate, anti-VEGF agents have the advantage over IVTA of being much less likely to cause cataract progression or a rise in IOP. However, they have less anti-inflammatory effect, making them less suitable for the treatment of CME primarily driven by inflammation [76] or if there is extensive breakdown of the bloodretina barrier [65]. The risk of serious cardiovascular events also remains controversial $[77,78]$.

\section{Anti-tumour necrosis factor (TNF)-a agents}

Local inhibition of TNF- $\alpha$ is a new and promising therapeutic direction, but clinical trials in patients have had mixed results. The initial rationale for injecting antiTNF- $\alpha$ drugs intraocularly was their efficacy when used systemically, even though their purported mechanism of action may not be effective when delivered locally [79-82]. Infliximab is a humanized, chimeric monoclonal antibody directed against TNF- $\alpha$ and clinical experience with its intravitreal use in uveitis is limited to one small pilot study of 10 eyes with chronic non-infectious uveitis that were unresponsive to systemic steroids [83]. Intravitreal injection of $1.5 \mathrm{mg}$ infliximab led to significant improvements in best corrected visual acuity, with a significant decrease in the central macular thickness and vitreous haze grading, but the follow-up period in this study was very short at four weeks. However, in one study in which $0.5 \mathrm{mg}$ infliximab was injected for either diabetic macular oedema or neovascular age related macular degeneration, intraocular inflammation developed in three of four treated eyes [84], and in another study in which eyes with refractory diabetic macular oedema were treated with $1-2 \mathrm{mg}$ infliximab, $42 \%$ of eyes receiving the $2 \mathrm{mg}$ dose developed severe uveitis, most of which subsequently required pars plana vitrectomy [85]. Not surprisingly, there has been a call for a moratorium on the clinical use of intravitreal infliximab outside of well-designed trials [86].

Adalimumab, a humanized monoclonal antibody against the soluble and membrane-bound TNF has recently been considered for intravitreal injection. Evidence of safety has been reported in rabbits [87], but clinical use in uveitic CME is limited to one small study of 8 eyes that were unresponsive to treatment with intraocular steroids and anti-VEGF injection. While there were no safety concerns with a dose of $1 \mathrm{mg}$, it failed to produce any significant improvement in vision or reduction of macular thickness [88]. Pre-clinical studies of the TNF inhibitor ESBA105 have also suggested good intravitreal and neuroretinal bioavailability [89], and it may be that newer agents can overcome the problems seen with the older chimeric antibody infliximab.

\section{Sirolimus}

Sirolimus, also known as rapamycin, was isolated in the 1970s from Streptomyces hygroscopicus in soil samples from Easter Island [90]. It is an immunosuppressant that works through inhibition of the mammalian target of rapamycin (mTOR) by binding to the immunophilin FK protein 12 (FKBP-12), and thus interrupts the inflammatory cascade that leads to T-cell activation and proliferation. It also suppresses $\mathrm{T}$-cell proliferation through the inhibition of IL-2, IL-4, and IL-15 via both calciumdependent and calcium-independent pathways [91]. A study of intravitreal and subconjunctival administration of sirolimus in 30 patients was recently reported in which it was reported to be safe and tolerable [16]. The results of a Phase III trial are currently awaited.

\section{Future directions}

Local treatment remains an attractive therapeutic option for uveitis, as it has the potential for avoiding systemic adverse events. Research continues into developing novel corticosteroids that maintain their anti-inflammatory effects whilst having an improved ocular side-effect profile, but the greatest hope must lie in the development of non-corticosteroid therapeutic options. In support of this goal, understanding of the pathophysiology of uveitis has advanced over the past decade, and mechanisms of ocular damage are increasingly being understood [92,93].

This is particularly true in the broad context of Matzinger's danger hypothesis, which helps to explain the ways in which the immune system is designed to detect self from non-self [94]. Non-infectious uveitis is generally understood as representing an autoimmune phenomenon, but experimental non-infectious uveitis requires initial activation of innate immunity prior to the generation of specific $\mathrm{T}$ cell responses, and there is good evidence to suggest that this also applies in human disease [92]. This presents a therapeutic opportunity as autoimmunity and autoinflammation evoke different molecular pathways that may generate different potential molecular targets. For example, improved understanding of how danger is sensed by the immune system, and how inflammasomes are subsequently involved in the activation of caspase- 1 to release IL-1 $\beta$ and IL-18 [95] leads to the potential for anti-IL-1 or anti-caspase- 1 therapies in some uveitic conditions [96]. Short interfering 
RNA (siRNA) approaches may also offer a mechanism by which to target caspases, and caspase- 2 has already been targeted successfully in an animal model of retinal ganglion cell loss [97]. Similarly, it may be possible to block pro-inflammatory cytokines such as IL-1 $\beta$ and IL-6 locally [89], or to target upstream so-called danger sensors, such as the purinergic ATP receptors [98], or even cell function regulators such as the sirtuins [99].

Other promising strategies include preventing cells from entering the target organ by inhibition of either adhesion or migration through endothelium (anti- $\alpha 4$-integrin (natalizumab)) [100], or via preventing efflux from lymph nodes by blocking sphingosine-1-phosphate receptor (fingolimod) [101], or targeting other effector cells, such as macrophages, through complement inhibition or stimulation of the CD200 macrophage inhibitory receptor. AntiCD20 (rituximab) has also shown efficacy when given systemically for orbital inflammation [102,103], although it has not been used intravitreally other than for lymphoma [104], and the efficacy of some of these treatments is helping to illuminate novel mechanistic pathways and challenge previous understanding of disease pathophysiology.

Furthermore, the advent of biotechnology is seeing advances in generation of new therapeutic molecules such as high affinity binding peptides or modified high affinity or bivalent single chain Fab fragments, offering higher specificity and possibility of topical delivery. For instance, the TNF- $\alpha$ inhibitory single-chain antibody fragment ESBA105 has been shown to reach therapeutic levels in all ocular compartments following topical administration in rabbits [105], and it is hoped that it will be possible to translate similar technology into clinical use. Indeed, the ability to deliver effective uveitis therapy to the posterior segment through the topical route truly would provide a step change to the advantages of local therapy.

\section{Conclusions}

In conclusion, the eye offers both a unique window on the functioning of the immune system and a unique opportunity for the effective local treatment of autoimmune and autoinflammatory disorders. Given the plethora of potential mechanisms and associated targets that increased understanding of its pathophysiology has introduced, it seems unlikely that the long-term future of therapy lies in corticosteroids, but instead that this increased knowledge will offer the opportunity for effective targeted treatment of the molecular mechanisms underlying ocular inflammation whilst minimising local and systemic side-effects.

\section{Competing interests}

ST has received consultancy fees from Allergan Inc. and Novartis Inc. This work has not previously been presented or reported in any form.

\section{Authors' contributions}

ST-R, $\perp$ and ST drafted the article, ST and AD edited the article. All authors read and approved the final manuscript.

\section{Financial support}

SRJT and LJ are supported by the UK National Institute of Health Research and by the Imperial NIHR Biomedical Research Centre. ST-R is supported by BBSRC and GlaxoSmithKline. ADD is supported by NIHR Biomedical Research Centre at Moorfields Eye Hospital NHS Foundation Trust and UCL Institute of Ophthalmology.

\section{Author details}

${ }^{1}$ Faculty of Medicine, Imperial College London, London, UK. ${ }^{2}$ Royal Surrey County Hospital NHS Foundation Trust, Guildford, Surrey, UK. ${ }^{3}$ UCL Institute of Ophthalmology, 11-43 Bath Street, London, UK. ${ }^{4} \mathrm{NIHR}$ Biomedical Research Centre at Moorfields Eye Hospital NHS Foundation Trust and UCL Institute of Ophthalmology, Bristol, UK. ${ }^{5}$ University of Bristol School of Clinical Sciences, Bristol, UK.

Received: 18 April 2013 Accepted: 1 August 2013

Published: 6 August 2013

\section{References}

1. Deschenes J, Murray PI, Rao NA, Nussenblatt RB: International Uveitis Study Group (IUSG): clinical classification of uveitis. Ocul Immunol Inflamm 2008, $16(1): 1-2$.

2. Jabs DA, Nussenblatt RB, Rosenbaum JT: Standardization of uveitis nomenclature for reporting clinical data. Results of the First International Workshop. Am J Ophthalmol 2005, 140(3):509-516.

3. Wakefield D, Chang JH, Amjadi S, Maconochie Z, Abu El-Asrar A, McCluskey P: What is new HLA-B27 acute anterior uveitis? Ocul Immunol Inflamm 2011, 19(2):139-144.

4. Taylor SR, Isa H, Joshi L, Lightman S: New developments in corticosteroid therapy for uveitis. Ophthalmologica 2010, 224(Suppl 1):46-53.

5. Sallam A, Taylor SR, Lightman S: Review and update of intraocular therapy in noninfectious uveitis. Curr Opin Ophthalmol 2011, 22(6):517-522.

6. Yeh S, Faia LJ, Nussenblatt RB: Advances in the diagnosis and immunotherapy for ocular inflammatory disease. Semin Immunopathol 2008, 30(2):145-164.

7. Mulki L, Foster CS: Difluprednate for inflammatory eye disorders. Drugs Today (Barc) 2011, 47(5):327-333.

8. Biswas J, Ganeshbabu TM, Raghavendran SR, Raizada S, Mondkar SV, Madhavan HN: Efficacy and safety of $1 \%$ rimexolone versus $1 \%$ prednisolone acetate in the treatment of anterior uveitis-a randomized triple masked study. Int Ophthalmol 2004, 25(3):147-153.

9. Loteprednol Etabonate US Uveitis Study Group: Controlled evaluation of loteprednol etabonate and prednisolone acetate in the treatment of acute anterior uveitis. Am J Ophthalmol 1999, 127(5):537-544.

10. Awan MA, Agarwal PK, Watson DG, McGhee CN, Dutton GN: Penetration of topical and subconjunctival corticosteroids into human aqueous humour and its therapeutic significance. Br J Ophthalmol 2009, 93(6):708-713.

11. Sohn EH, Wang R, Read R, Roufas A, Teo L, Moorthy R, Albini T, VasconcelosSantos DV, Dustin LD, Zamir E, et al: Long-term, multicenter evaluation of subconjunctival injection of triamcinolone for non-necrotizing, noninfectious anterior scleritis. Ophthalmology 2011, 118(10):1932-1937.

12. Kim SJ, Flach AJ, Jampol LM: Nonsteroidal anti-inflammatory drugs in ophthalmology. Surv Ophthalmol 2010, 55(2):108-133.

13. Crosby-Nwaobi R, Sivaprasad S, Forbes A: A systematic review of the association of diabetic retinopathy and cognitive impairment in people with Type 2 diabetes. Diabetes research and clinical practice 2012, 96(2):101-110.

14. Nussenblatt RB, Dinning WJ, Fujikawa LS, Chan CC, Palestine AG: Local cyclosporine therapy for experimental autoimmune uveitis in rats. Arch Ophthalmol 1985, 103(10):1559-1562.

15. Sasamoto $Y$, Hirose $S$, Ohno S, Onoe K, Matsuda H: Topical application of ciclosporin ophthalmic solution containing alpha-cyclodextrin in experimental uveitis. Ophthalmologica 1991, 203(3):118-125.

16. Nguyen QD, Ibrahim MA, Watters A, Bittencourt M, Yohannan J, Sepah YJ, Dunn JP, Naor J, Shams N, Shaikh O, et al: Ocular tolerability and efficacy of intravitreal and subconjunctival injections of sirolimus in patients with non-infectious uveitis: primary 6-month results of the SAVE Study. J Ophthalmic Inflamm Infect 2013, 3(1):32.

17. Lightman S, Kok H: Developments in the treatment of uveitis. Expert Opin Investig Drugs 2002, 11(1):59-67.

18. Ferrante $P$, Ramsey A, Bunce C, Lightman S: Clinical trial to compare efficacy and side-effects of injection of posterior sub-Tenon 
triamcinolone versus orbital floor methylprednisolone in the management of posterior uveitis. Clin Experiment Ophthalmol 2004, 32(6):563-568

19. Helm CJ, Holland GN: The effects of posterior subtenon injection of triamcinolone acetonide in patients with intermediate uveitis. Am $J$ Ophthalmol 1995, 120(1):55-64

20. Roesel M, Heinz C, Koch JM, Heiligenhaus A: Comparison of orbital floor triamcinolone acetonide and oral prednisolone for cataract surgery management in patients with non-infectious uveitis. Graefes Arch Clin Exp Ophthalmol 2010, 248(5):715-720.

21. Gaudio PA: A review of evidence guiding the use of corticosteroids in the treatment of intraocular inflammation. Ocul Immunol Inflamm 2004, 12(3):169-192.

22. Nan K, Sun S, Li Y, Qu J, Li G, Luo L, Chen H, Cheng L: Characterisation of systemic and ocular drug level of triamcinolone acetonide following a single sub-Tenon injection. Br J Ophthalmol 2010, 94(5):654-658.

23. Roesel M, Gutfleisch M, Heinz C, Heimes B, Zurek-Imhoff B, Heiligenhaus A: Orbital floor triamcinolone acetonide injections for the management of active non-infectious uveitis. Eye (Lond) 2009, 23(4):910-914.

24. Byun YS, Park YH: Complications and safety profile of posterior subtenon injection of triamcinolone acetonide. J Ocul Pharmacol Ther 2009, 25(2):159-162.

25. Roesel M, Gutfleisch M, Heinz C, Heimes B, Zurek-Imhoff B, Heiligenhaus A: Intravitreal and orbital floor triamcinolone acetonide injections in noninfectious uveitis: a comparative study. Ophthalmic Res 2009, 42(2):81-86.

26. Riordan-Eva P, Lightman S: Orbital floor steroid injections in the treatment of uveitis. Eye (Lond) 1994, 8(Pt 1):66-69.

27. Chalam KV, Malkani S, Shah VA: Intravitreal dexamethasone effectively reduces postoperative inflammation after vitreoretinal surgery. Ophthalmic Surg Lasers Imaging 2003, 34(3):188-192.

28. Gan IM, Ugahary LC, van Dissel JT, Feron E, Peperkamp E, Veckeneer M, Mulder PG, Platenkamp GJ, van Meurs JC: Intravitreal dexamethasone as adjuvant in the treatment of postoperative endophthalmitis: a prospective randomized trial. Graefes Arch Clin Exp Ophthalmol 2005, 243(12):1200-1205.

29. Sallam A, Taylor SR, Habot-Wilner Z, Elgohary M, Do HH, McCluskey P, Lightman S: Repeat intravitreal triamcinolone acetonide injections in uveitic macular oedema. Acta Ophthalmol 2012, 90(4):e323-e325.

30. Inoue M, Takeda K, Morita K, Yamada M, Tanigawara Y, Oguchi Y: Vitreous concentrations of triamcinolone acetonide in human eyes after intravitreal or subtenon injection. Am J Ophthalmol 2004, 138(6):1046-1048.

31. van Kooij B, Rothova A, de Vries P: The pros and cons of intravitreal triamcinolone injections for uveitis and inflammatory cystoid macular edema. Ocul Immunol Inflamm 2006, 14(2):73-85.

32. Couch SM, Bakri SJ: Intravitreal triamcinolone for intraocular inflammation and associated macular edema. Clin Ophthalmol 2009, 3:41-47.

33. Kok H, Lau C, Maycock N, McCluskey P, Lightman S: Outcome of intravitreal triamcinolone in uveitis. Ophthalmology 2005, 112(11):1916. e1911-1917.

34. Maca SM, Abela-Formanek C, Kiss CG, Sacu SG, Benesch T, BarisaniAsenbauer T: Intravitreal triamcinolone for persistent cystoid macular oedema in eyes with quiescent uveitis. Clin Experiment Ophthalmol 2009, 37(4):389-396

35. Kiernan DF, Mieler WF: The use of intraocular corticosteroids. Expert Opin Pharmacother 2009, 10(15):2511-2525.

36. Baath J, Ells AL, Crichton A, Kherani A, Williams RG: Safety profile of intravitreal triamcinolone acetonide. J Ocul Pharmacol Ther 2007, 23(3):304-310.

37. Tan DT, Chee SP, Lim L, Lim AS: Randomized clinical trial of a new dexamethasone delivery system (Surodex) for treatment of post-cataract surgery inflammation. Ophthalmology 1999, 106(2):223-231.

38. Chang DF, Garcia IH, Hunkeler JD, Minas T: Phase II results of an intraocular steroid delivery system for cataract surgery. Ophthalmology 1999, 106(6):1172-1177.

39. Tan DT, Chee SP, Lim L, Theng J, Van Ede M: Randomized clinical trial of Surodex steroid drug delivery system for cataract surgery: anterior versus posterior placement of two Surodex in the eye. Ophthalmology 2001, 108(12):2172-2181

40. da Silva GR, da Silva Cunha A Jr, Ayres E, Orefice RL: Effect of the macromolecular architecture of biodegradable polyurethanes on the controlled delivery of ocular drugs. J Mater Sci Mater Med 2009, 20(2):481-487.

41. Lowder C, Belfort R Jr, Lightman S, Foster CS, Robinson MR, Schiffman RM, Li XY Cui H, Whitcup SM, Ozurdex HSG: Dexamethasone intravitreal implant for noninfectious intermediate or posterior uveitis. Arch Ophthalmol 2011, 129 (5):545-553.
42. Taylor SR, Tomkins-Netzer O, Joshi L, Morarji J, McLoone E, Lightman S: Dexamethasone implant in pediatric uveitis. Ophthalmology 2012, 119(11):2412-2412. e2412.

43. Driot JY, Novack GD, Rittenhouse KD, Milazzo C, Pearson PA: Ocular pharmacokinetics of fluocinolone acetonide after Retisert intravitreal implantation in rabbits over a 1-year period. J Ocul Pharmacol Ther 2004 20(3):269-275

44. Mruthyunjaya P, Khalatbari D, Yang P, Stinnett S, Tano R, Ashton P, Guo H, Nazzaro M, Jaffe GJ: Efficacy of low-release-rate fluocinolone acetonide intravitreal implants to treat experimental uveitis. Arch Ophthalmol 2006, 124(7):1012-1018.

45. Jaffe GJ, Martin D, Callanan D, Pearson PA, Levy B, Comstock T: Fluocinolone acetonide implant (Retisert) for noninfectious posterior uveitis: thirty-four-week results of a multicenter randomized clinical study. Ophthalmology 2006, 113(6):1020-1027.

46. Park UC, Kim SJ, Yu HG: Cytomegalovirus endotheliitis after fluocinolone acetonide (Retisert) implant in a patient with Behcet uveitis. Ocul Immunol Inflamm 2011, 19(4):282-283.

47. Malone PE, Herndon LW, Muir KW, Jaffe GJ: Combined fluocinolone acetonide intravitreal insertion and glaucoma drainage device placement for chronic uveitis and glaucoma. Am J Ophthalmo/ 2010, 149(5):800-806. e801

48. Chieh JJ, Carlson AN, Jaffe GJ: Combined fluocinolone acetonide intraocular delivery system insertion, phacoemulsification, and intraocular lens implantation for severe uveitis. Am J Ophthalmol 2008, 146(4):589-594.

49. Multicenter Uveitis Steroid Treatment Trial Research G, Kempen JH, Altaweel MM, Holbrook JT, Jabs DA, Louis TA, Sugar EA, Thorne JE: Randomized comparison of systemic anti-inflammatory therapy versus fluocinolone acetonide implant for intermediate, posterior, and panuveitis: the multicenter uveitis steroid treatment trial. Ophthalmology 2011, 118(10):1916-1926.

50. Kane FE, Burdan J, Cutino A, Green KE: lluvien: a new sustained delivery technology for posterior eye disease. Expert Opin Drug Deliv 2008, 5(9):1039-1046.

51. Campochiaro PA, Hafiz G, Shah SM, Bloom S, Brown DM, Busquets M, Ciulla T, Feiner L, Sabates N, Billman K, et al: Sustained ocular delivery of fluocinolone acetonide by an intravitreal insert. Ophthalmology 2010, 117(7):1393-1399.

52. Barnett PJ: Mathematical modeling of triamcinolone acetonide drug release from the I-vation intravitreal implant (a controlled release platform). Conf Proc IEEE Eng Med Biol Soc 2009, 2009:3087-3090.

53. Rabiah PK, Fiscella RG, Tessler HH: Intraocular penetration of periocular ketorolac and efficacy in experimental uveitis. Invest Ophthalmol Vis Sci 1996, 37(4):613-618.

54. Kim SJ, Doherty TJ, Cherney EF: Intravitreal ketorolac for chronic uveitis and macular edema: a pilot study. Arch Ophthalmol 2012, 130(4):456-460

55. Soheilian M, Karimi S, Ramezani A, Peyman GA: Pilot study of intravitreal injection of diclofenac for treatment of macular edema of various etiologies. Retina 2010, 30(3):509-515.

56. Fishburne BC, Wilson DJ, Rosenbaum JT, Neuwelt EA: Intravitreal methotrexate as an adjunctive treatment of intraocular lymphoma. Arch Ophthalmol 1997, 115(9):1152-1156.

57. Smith JR, Rosenbaum JT, Wilson DJ, Doolittle ND, Siegal T, Neuwelt EA Pe'er J: Role of intravitreal methotrexate in the management of primary central nervous system lymphoma with ocular involvement. Ophthalmology 2002, 109(9):1709-1716

58. Hardwig PW, Pulido JS, Erie JC, Baratz KH, Buettner H: Intraocular methotrexate in ocular diseases other than primary central nervous system lymphoma. Am J Ophthalmol 2006, 142(5):883-885

59. Taylor SR, Habot-Wilner Z, Pacheco P, Lightman SL: Intraocular methotrexate in the treatment of uveitis and uveitic cystoid macular edema. Ophthalmology 2009, 116(4):797-801.

60. Taylor SR, Habot-Wilner Z, Pacheco P, Lightman S: Intravitreal methotrexate in uveitis. Ophthalmology 2012, 119(4):878-879.

61. Taylor SR, Banker AJ, Schlaen A, Joshi L, McCluskey P, Lightman S: Intravitreal methotrexate can induce long-term remission in some patients with non-infectious uveitis. Retina 2013. In Press.

62. He Y, Liu Y, Liu Y, Wang J, Zhang X, Lu W, Ma Z, Zhu X, Zhang Q: Cyclosporine-loaded microspheres for treatment of uveitis: in vitro characterization and in vivo pharmacokinetic study. Invest Ophthalmol Vis Sci 2006, 47(9):3983-3988. 
63. Oh-i K, Keino H, Goto H, Yamakawa N, Murase K, Usui Y, Kezuka T, Sakai J, Takeuchi M, Usui M: Intravitreal injection of Tacrolimus (FK506) suppresses ongoing experimental autoimmune uveoretinitis in Rats. Br J Ophthalmol 2007, 91(2):237-242.

64. Ishikawa T, Hokama H, Katagiri Y, Goto H, Usui M: Effects of intravitreal injection of tacrolimus (FK506) in experimental uveitis. Curr Eye Res 2005, 30(2):93-101.

65. Weiss K, Steinbrugger I, Weger M, Ardjomand N, Maier R, Wegscheider BJ, Wedrich A, El-Shabrawi Y: Intravitreal VEGF levels in uveitis patients and treatment of uveitic macular oedema with intravitreal bevacizumab. Eye (Lond) 2009, 23(9):1812-1818.

66. Fine HF, Baffi J, Reed GF, Csaky KG, Nussenblatt RB: Aqueous humor and plasma vascular endothelial growth factor in uveitis-associated cystoid macular edema. Am J Ophthalmol 2001, 132(5):794-796.

67. Huang S, Robinson JB, Deguzman A, Bucana CD, Fidler IJ: Blockade of nuclear factor-kappaB signaling inhibits angiogenesis and tumorigenicity of human ovarian cancer cells by suppressing expression of vascular endothelial growth factor and interleukin 8. Cancer Res 2000, 60(19):5334-5339.

68. van Kooij B, Rothova A, Rijkers GT, de Groot-Mijnes JD: Distinct cytokine and chemokine profiles in the aqueous of patients with uveitis and cystoid macular edema. Am J Ophthalmol 2006, 142(1):192-194.

69. Cohen T, Nahari D, Cerem LW, Neufeld G, Levi BZ: Interleukin 6 induces the expression of vascular endothelial growth factor. J Biol Chem 1996, 271(2):736-741.

70. Cordero Coma M, Sobrin L, Onal S, Christen W, Foster CS: Intravitreal bevacizumab for treatment of uveitic macular edema. Ophthalmology 2007, 114(8):1574-1579. e1571.

71. Mackensen F, Heinz C, Becker MD, Heiligenhaus A: Intravitreal bevacizumab (avastin) as a treatment for refractory macular edema in patients with uveitis: a pilot study. Retina 2008, 28(1):41-45.

72. Acharya NR, Hong KC, Lee SM: Ranibizumab for refractory uveitis-related macular edema. Am J Ophthalmol 2009, 148(2):303-309. e302.

73. Lasave AF, Zeballos DG, El-Haig WM, Diaz-Llopis M, Salom D, Arevalo JF: Short-term results of a single intravitreal bevacizumab (avastin) injection versus a single intravitreal triamcinolone acetonide (kenacort) injection for the management of refractory noninfectious uveitic cystoid macular edema. Ocul Immunol Inflamm 2009, 17(6):423-430.

74. Bae JH, Lee CS, Lee SC: Efficacy and safety of intravitreal bevacizumab compared with intravitreal and posterior sub-tenon triamcinolone acetonide for treatment of uveitic cystoid macular edema. Retina 2011, 31(1):111-118.

75. Soheilian M, Rabbanikhah Z, Ramezani A, Kiavash V, Yaseri M, Peyman GA: Intravitreal bevacizumab versus triamcinolone acetonide for refractory uveitic cystoid macular edema: a randomized pilot study. J Ocul Pharmacol Ther 2010, 26(2):199-206.

76. Cervantes-Castaneda RA, Giuliari GP, Gallagher MJ, Yilmaz T, MacDonell RE, Quinones K, Foster CS: Intravitreal bevacizumab in refractory uveitic macular edema: one-year follow-up. Eur J Ophthalmol 2009, 19(4):622-629.

77. Rosenfeld PJ, Brown DM, Heier JS, Boyer DS, Kaiser PK, Chung CY, Kim RY: Ranibizumab for neovascular age-related macular degeneration. N Engl J Med 2006, 355(14):1419-1431.

78. Brown DM, Kaiser PK, Michels M, Soubrane G, Heier JS, Kim RY, Sy JP, Schneider S: Ranibizumab versus verteporfin for neovascular age-related macular degeneration. N Engl J Med 2006, 355(14):1432-1444.

79. Markomichelakis NN, Theodossiadis PG, Pantelia E, Papaefthimiou S, Theodossiadis GP, Sfikakis PP: Infliximab for chronic cystoid macular edema associated with uveitis. Am J Ophthalmol 2004, 138(4):648-650.

80. Sfikakis PP, Kaklamanis PH, Elezoglou A, Katsilambros N, Theodossiadis PG, Papaefthimiou S, Markomichelakis N: Infliximab for recurrent, sightthreatening ocular inflammation in Adamantiades-Behcet disease. Ann Intern Med 2004, 140(5):404-406.

81. Sfikakis PP, Theodossiadis PG, Katsiari CG, Kaklamanis P, Markomichelakis NN: Effect of infliximab on sight-threatening panuveitis in Behcet's disease. Lancet 2001, 358(9278):295-296.

82. Theodossiadis PG, Markomichelakis NN, Sfikakis PP: Tumor necrosis factor antagonists: preliminary evidence for an emerging approach in the treatment of ocular inflammation. Retina 2007, 27(4):399-413.

83. Farvardin M, Afarid M, Mehryar M, Hosseini $\mathrm{H}$ : Intravitreal infliximab for the treatment of sight-threatening chronic noninfectious uveitis. Retina 2010, 30(9):1530-1535.

84. Giganti M, Beer PM, Lemanski N, Hartman C, Schartman J, Falk N: Adverse events after intravitreal infliximab (Remicade). Retina 2010, 30(1):71-80.
85. Wu L, Hernandez-Bogantes E, Roca JA, Arevalo JF, Barraza K, Lasave AF: intravitreal tumor necrosis factor inhibitors in the treatment of refractory diabetic macular edema: a pilot study from the Pan-American Collaborative Retina Study Group. Retina 2011, 31(2):298-303.

86. Pulido JS, Pulido JE, Michet CJ, Vile RG: More questions than answers: a call for a moratorium on the use of intravitreal infliximab outside of a well-designed trial. Retina 2010, 30(1):1-5.

87. Tsilimbaris M, Diakonis VF, Naoumidi I, Charisis S, Kritikos I, Chatzithanasis G, Papadaki T, Plainis S: Evaluation of potential retinal toxicity of adalimumab (Humira). Graefes Arch Clin Exp Ophthalmol 2009, 247(8):1119-1125.

88. Androudi S, Tsironi E, Kalogeropoulos C, Theodoridou A, Brazitikos P: Intravitreal adalimumab for refractory uveitis-related macular edema. Ophthalmology 2010, 117(8):1612-1616.

89. Dick AD: Road to fulfilment: taming the immune response to restore vision. Ophthalmic Res 2012, 48(1):43-49.

90. Napoli KL, Taylor PJ: From beach to bedside: history of the development of sirolimus. Ther Drug Monit 2001, 23(5):559-586.

91. Sehgal SN: Rapamune (RAPA, rapamycin, sirolimus): mechanism of action immunosuppressive effect results from blockade of signal transduction and inhibition of cell cycle progression. Clin Biochem 1998, 31(5):335-340.

92. Willermain F, Rosenbaum JT, Bodaghi B, Rosenzweig HL, Childers S, Behrend T, Wildner G, Dick AD: Interplay between innate and adaptive immunity in the development of non-infectious uveitis. Prog Retin Eye Res 2012, 31(2):182-194.

93. de Smet MD, Taylor SR, Bodaghi B, Miserocchi E, Murray PI, Pleyer U, Zierhut M, Barisani-Asenbauer T, LeHoang P, Lightman S: Understanding uveitis: the impact of research on visual outcomes. Prog Retin Eye Res 2011, 30(6):452-470.

94. Matzinger P: The danger model: a renewed sense of self. Science 2002, 296(5566):301-305.

95. Schroder K, Zhou R, Tschopp J: The NLRP3 inflammasome: a sensor for metabolic danger? Science 2010, 327(5963):296-300.

96. Yu JR, Leslie KS: Cryopyrin-associated periodic syndrome: an update on diagnosis and treatment response. Current allergy and asthma reports 2011, 11(1):12-20.

97. Ahmed Z, Kalinski H, Berry M, Almasieh M, Ashush H, Slager N, Brafman A, Spivak I, Prasad N, Mett I, et al: Ocular neuroprotection by siRNA targeting caspase-2. Cell death \& disease 2011, 2:e173.

98. Taylor SR, Turner CM, Elliott JI, McDaid J, Hewitt R, Smith J, Pickering MC, Whitehouse DL, Cook HT, Burnstock G, et al: P2X7 deficiency attenuates renal injury in experimental glomerulonephritis. J Am Soc Nephrol 2009, 20(6):1275-1281.

99. Gardner PJ, Joshi L, Lee RW, Dick AD, Adamson P, Calder VL: SIRT1 activation protects against autoimmune $T$ cell-driven retinal disease in mice via inhibition of IL-2/Stat5 signaling. J Autoimmun 2013, 42:117-129.

100. Goodin DS, Cohen BA, O'Connor P, Kappos L, Stevens JC, Therapeutics, Technology Assessment Subcommittee of the American Academy of $\mathrm{N}$ : Assessment: the use of natalizumab (Tysabri) for the treatment of multiple sclerosis (an evidence-based review): report of the Therapeutics and Technology Assessment Subcommittee of the American Academy of Neurology. Neurology 2008, 71(10):766-773.

101. Raveney BJ, Copland DA, Nicholson LB, Dick AD: Fingolimod (FTY720) as an acute rescue therapy for intraocular inflammatory disease. Arch Ophthalmol 2008, 126(10):1390-1395.

102. Joshi L, Lightman SL, Salama AD, Shirodkar AL, Pusey CD, Taylor SR: Rituximab in refractory ophthalmic Wegener's granulomatosis: PR3 titers may predict relapse, but repeat treatment can be effective. Ophthalmology 2011, 118(12):2498-2503.

103. Taylor SR, Salama AD, Joshi L, Pusey CD, Lightman SL: Rituximab is effective in the treatment of refractory ophthalmic Wegener's granulomatosis. Arthritis Rheum 2009, 60(5):1540-1547.

104. Yeh S, Wilson DJ: Combination intravitreal rituximab and methotrexate for massive subretinal lymphoma. Eye (Lond) 2010, 24(10):1625-1627.

105. Furrer E, Berdugo M, Stella C, Behar-Cohen F, Gurny R, Feige U, Lichtlen P, Urech DM: Pharmacokinetics and posterior segment biodistribution of ESBA105, an anti-TNF-alpha single-chain antibody, upon topical administration to the rabbit eye. Invest Ophthalmol Vis Sci 2009, 50(2):771-778

doi:10.1186/1471-2415-13-39

Cite this article as: Tempest-Roe et al.: Local therapies for inflammatory eye disease in translation: past, present and future. BMC Ophthalmology 2013 13:39. 